\title{
Konjenital Skolyoz Tanı ve Tedavisi
}

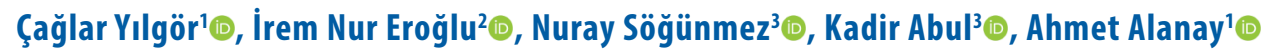

\author{
${ }^{1}$ Acıbadem Mehmet Ali Aydınlar \\ Üniversitesi, Tıp Fakültesi, Ortopedi ve \\ Travmatoloji Anabilim Dalı, İstanbul, \\ Türkiye \\ ${ }^{2}$ Acıbadem Mehmet Ali Aydınlar \\ Üniversitesi, Tıp Fakültesi, İstanbul, \\ Türkiye \\ ${ }^{3}$ Acıbadem Maslak Hastanesi, Omurga \\ Sağlığı Merkezi, İstanbul, Türkiye
}

Çağlar Yılgör, Doç. Dr. İrem Nur Eroğlu, Öğrenci Nuray Söğünmez, MSc. Kadir Abul, 0p. Dr. Ahmet Alanay, Prof. Dr.

İletişim:

Prof. Dr. Ahmet Alanay

Acıbadem Mehmet Ali Aydınlar Üniversitesi, Tıp Fakültesi, Ortopedi ve Travmatoloji Anabilim Dalı, İstanbul, Türkiye

Tel: +905322766816

E-Posta: aalanay@gmail.com

Gönderilme Tarihi : 23 Haziran 2017

Revizyon Tarihi : 16 Eylül 2017

Kabul Tarihi : 17 Eylül 2017

\section{ÖZET}

Omurganın en sık görülen konjenital deformitesi konjenital skolyozdur. Deformiteyi oluşturan sebep, oluşum veya ayrışma kusuru veya bu iki bozukluğun birlikte olduğu karma tiptir. Kliniğe yansıması, stabil hemivertebradan, pulmoner, kardiyak, genitoüriner ve nörolojik komplikasyonlara yol açabilen karmaşık ve ilerleyici deformitelere kadar geniş bir aralıktadır. Tabloya sıkıkla diğer organ sistemlerindeki anomaliler eşlik eder. Tanıda; prenatal ultrason, fizik muayene ve röntgen kullanılır. Manyetik rezonans eşlik eden intradural patolojilerin ortaya konulmasında yardımcıdır. Bilgisayarlı tomografi cerrahi planlamada yardımcı olabilir. Tedavi planı eğriliğin yeri ve derecesi, hastanın yaşı, deformitenin tipine ve öngörülen ilerleme beklentisine göre her hastaya özel olarak yapıIır. Tedavi temel olarak kontrollü gözlem, konservatif ve cerrahi tedavilerden oluşur. Tek hemivertebra varlığında genellikle erken yaşta hemivertebrektomi ve limitli füzyon önerilir. Daha karmaşık deformitelerde hemiepifizyodez, distraksiyon temelli füzyonsuz cerrahi yöntemler veya bunların kombinasyonları kullanılabilir. Günümüzde teknolojik ilerlemeler sayesinde spinal deformite ve intradural patolojilerin cerrahisi eş zamanlı olarak güvenli şekilde yapılabilmektedir. İhmal edilmiş ileri deformitelerde düzeltici osteotomiler gerekebilir. Düzeltici osteotomiler barındırdıkları nörolojik yaralanma riski ve uygulamadaki teknik zorluklar nedeniyle donanımlı merkezlerde deneyimli cerrahlar tarafından gerçekleştirilmelidir.

Anahtar sözcükler: Omurga, doğumsal anomaliler, skolyoz, kifoz, hemivertebra

\section{ABSTRACT}

Congenital scoliosis is the most common congenital spinal deformity caused by a failure in the formation or segmentation or both. Clinical manifestations may vary from stable hemivertebra to complex deformities that can lead to pulmonary, cardiac, genitourinary and neurological complications. Other system anomalies may accompany as well. Prenatal ultrasound, physical examination and x-rays are used for diagnosis. MR is helpful in detecting accompanying pathologies. CT may be useful in preoperative planning. The treatment plan is tailored to each patient according to location and magnitude of the curve, patient age, type of the deformity and the anticipated natural history. Treatment consists of controlled observation, conservative and surgical methods. Hemivertebrectomy and limited fusion are recommended at an early age for single hemivertebra. Hemiepiphysiodesis, distraction-based non-fusion methods or combinations of these may be used for more complex deformities. Technological advances today allow for concurrent surgeries for spinal deformity and intradural pathologies. Corrective osteotomies may be required in neglected severe cases. Due to the challenging technique and risk of neurological injury, corrective osteotomies necessitate well-equipped centers and experienced surgeons.

Keywords: Spine, congenital abnormalities, scoliosis, kyphosis, hemivertebrae 
K onjenital skolyoz, omurganın oluşum, ayrışma veya her iki evresinde bozulma ile ortaya çıkan doğumsal bir şekil bozukluğudur. Omurganın en sık görülen konjenital deformitesidir. Bunu konjenital kifoz ve konjenital lordoz takip eder $(1,2)$. Yaklaşık prevelans her 1000 canlı doğumda 13-51 olarak bildirilmekle birlikte, tıbbi yardıma başvurmayan asemptomatik vakaların olabilmesi nedeniyle genel popülasyondaki gerçek insidansının belirlenmesi zor olan yaygın bir deformitedir (3). Asemptomatik deformiteler olabileceği gibi, konjenital skolyoz yaşamı tehdit edebilecek ağır deformitelere de neden olabilir. Kliniğe yansıması, ilerleme göstermeyen stabil hemivertebralardan, pulmoner, kardiyak, nörolojik, renal, ve göğüs kafesi komplikasyonlarına yol açabilen çok daha karmaşık ve ilerleyici vakalara kadar çok geniş bir aralıktadır (4). Bu nedenle hem tanısı, hem de tedavisi ciddi önem taşımaktadır.

Omurga çeşitli embriyolojik gelişim aşamalarından geçerek bilinen karmaşık anatomik yapısına ulaşır. Öncelikle orta hatta notokord oluşur. Notokordun iki yanında kafadan kuyruk sokumuna doğru sırayla 42-44 çift somit para-aksiyel mezodermi oluşturur. Bir omurun normal anatomide oluşması için iki somitin notokordun önünde ve arkasında buluşması ve etkileşmesi gerekir. Oluşma aşaması tamamlandıktan sonra spinal sinirlerin arada kalması ve disklerin oluşması ile omurlar birbirinden ayrışır (5). Konjenital skolyozun, gebeliğin beş ile sekizinci haftaları arasında fetal omurga gelişimini etkileyen bir bozukluk sonucu ortaya çıktığı düşünülmektedir $(1,6)$. Gebeliğin dört ile altıncı haftaları arasında gelişen omurganın embriyogenezdeki gelişim aşamaları genitoüriner, kas-iskelet ve kardiyovasküler sistemlerdeki gelişimler ile paralellik gösterir (4). Bu nedenle, konjenital skolyoza sıklıkla diğer organ sistemlerinde anomaliler de eşlik eder.

Embriyogenezde omurga oluşum ve ayrışma basamaklarını düzenleyen çeşitli genlerdeki mutasyonların konjenital skolyoza neden olabildiği varsayılmakla birlikte genel olarak etyolojisi heterojen olarak kabul edilir. Genetik faktörlerin yanı sıra hamilelik sürecinde hipoksiye, alkole, valproik aside ve hipertermiye maruz kalma gibi epigenetik faktörlerin de konjenital skolyoz oluşumda rolü olduğu bilinmektedir (6-8). Konjenital skolyoz, çoğu olguda kalıtsal değildir (1).

Konjenital skolyoz geniş bir klinik yelpazede ortaya çıkabildiği için, hem tanı hem de tedavi aşamasında doğru kararların verilebilmesi, deformite tiplerinin tanınması ve bu tiplerin davranış kalıplarının anlaşılması çok önemlidir. Tanı için klinik muayene ve çeşitli görüntüleme yöntemleri kullanılır. Tedavi stratejisi ise hem eğriliğin mevcut derecesine hem de öngörülen ilerleme beklentisine göre belirlenir (9).

\section{Tanı}

Günümüzde ilerleyen teknoloji ve artan farkındalık ile birlikte intrauterin tanı mümkündür. Birçok hemivertebra prenatal ultrasonda tanı almaktadır (1). Klasik tanı yöntemi ise klinik muayene ve konvansiyonel röntgendir. Muayenede koronal ve sagital denge, pelvis ve omuz dengesi, gövde kayması, hörgüç bulgusunun yanı sıra eğriliğin esnekliği de değerlendirilir. Klinik fotoğraf çekilmesi de muayenenin önemli bir parçasıdır (1). Bilgisayarlı tomografi anatomik kemik yapının ve bozukluğun çok daha ayrıntılı olarak ortaya konulmasını sağlar. Ancak küçük yaşta radyasyon maruziyetini kısıtlamak amacıyla genellikle cerrahi planlama aşamasında önerilir $(10,11)$. Eşlik edebilecek intraspinal patolojilerin tanınması ve anomali içerisinde kalan omurlar arası disklerin durumunun daha iyi değerlendirilmesi için genellikle her vakada tüm omurganın manyetik rezonans görüntülemesi önerilir (4).

\section{Sinıflandirma}

Konjenital skolyoz vertebra anomalisinin lokalizasyonuna ve türüne göre tanımlanır (12). Omurga anomalilerinin yaklaşık 1/3'ü üst, 1/3'ü ana torasik, 1/5'i ise torakolomberdir. Hastaların \%10'unda lomber, \%5'inde ise lumbosakral yerleşimlidir $(13,14)$. Deformiteyi oluşturan sebep oluşum veya ayrışma kusuru olarak ikiye ayrılsa da birçok hastada bu iki bozukluğun birlikte olduğu karma tip görülür (15).

Oluşum kusuru inkomplet olduğunda kama vertebra, komplet olduğunda ise hemivertebra ile sonuçlanır. Kama vertebranın her iki pedikülü de mevcuttur, fakat bir tarafı hipoplastik olup asimetrik bir yükseklik gösterir (7). Hemivertebra'da ise bir pedikül eksiktir; yarım omur gövdesi ve yarım lamina vardır (15). Hemivertebralar, konjenital skolyozun en sık görülen tipidir (16). Üst ve alttaki vertebra ile aralarında disk bulunup bulunmama durumuna göre tam ayrışmış hemivertebra, kısmen ayrışmış hemivertebra ve ayrışmamış hemivertebra olarak üçe ayrılırlar. Tam ayrışmış hemivertebra, normal disk boşluklarıyla bir alt ve bir üst vertebra gövdelerinden tamamen ayrılmıştır. Kısmen ayrışmış hemivertebra bir üst veya alttaki omurgaya kaynaşırken, açık bir disk alanı ile diğerinden ayrılır. Ayrışmamış hemivertebra (hapsolmuş), disk alanı olmaksızın iki bitişik omurgayla kaynaşmıştır $(4,15)$.

Oluşum kusuru tek bir vertebra ile sınırlı kalmayabilir. Eğer oluşum kusurları omurganın farklı seviyelerinde aynı 
tarafta ise asimetrik büyüme ve ilerleme potansiyeli daha fazladır (7). Hemivertebraların omurganın farklı seviyelerinde karşılıklı yerleşmiş olması durumu ise hemimetamerik kayma olarak adlandırılır ve genellikle birbirini dengeleyerek daha düşük ilerleme potansiyeli gösterir (17).

Ayrışma kusurları bilateral olduğunda blok vertebra oluşur. Tek taraflı ayrışma kusurları konjenital bar olarak adlandırılır. Bar olan kısımda büyüme engellendiği ve karşı taraf büyümeye devam ettiği için eğrilik gelişir.

Oluşum ve ayrışma kusurlarının bir arada bulunduğu deformiteler karma tip olarak adlandırılır. Konjenital barın karşı tarafında hemivertebra bulunması karma tipe örnek olarak verilebilir ve ciddi ilerleme potansiyeline sahiptir (12).

\section{Doğal seyir}

Konjenital skolyozda tedavinin belirlenmesi doğal seyrin iyi anlaşılmasına bağlıdır. Verilecek olan tedavi kararı eğriliğin ilerleyip ilerlemeyeceğine, ilerleyici eğriliklerde ise ilerleme hızına göre değişiklik gösterir (2). Eğriliklerin ilerleme potansiyeli temel olarak 3 şeye bağlıdır: eğriliğin yerleşimi, anomalinin tipi ve hastanın yaşı $(4,18)$. Bu üç faktör, asimetrik büyüme potansiyelini ve hastanın kalan büyümesini tahmin etmekte kullanılır. Lomber ve torakolomber yerleşimli deformiteler üst torasik yerleşimli olanlara göre daha fazla ilerleme eğilimindedir $(2,16)$. Asimetrik büyüme potansiyelini belirlemede en önemli ipucu anomalili omurganın çevresindeki disklerin varlığıdır (12). Kabaca, konjenital skolyoz vakalarının \%25'inin stabil olduğu, \%25'inin hafif \%50'sinin ise hızlı progresyon göstereceği öngörülmüştür (1).

Blok vertebra, kama vertebra, unilateral bar ve ayrışmamış hemivertebra düşük progresyon potansiyeline sahiptir ve blok vertebra bunlar içerisinde en düşük riski taşır $(3,4)$. Komşu vertebralardan kısmen ayrışmış ve tam ayrışmış hemivertebralar aralarında sağlıklı disk alanlarına sahip olduğundan daha yüksek ilerleme riski taşırlar $(3,4)$. ilerleme potansiyeli en yüksek olan tablo hemivertebraya eşlik eden karşı tarafta unilateral bar olmasıdır. Bu tarz deformiteler çoğunlukla kompensatuar eğrilik, pelvik oblikite ve gövde kayması gibi bulgularla birlikte olur $(7,19)$. Farklı oluşum ve ayrışma kusurlarını bir arada içeren karma tiplerde doğal seyri tahmin etmek daha zor olabilir (12).

\section{Eşlik eden anomaliler}

Konjenital skolyoza omurganın ve omuriliğin çeşitli anomalileri eşlik edebilir: diastematomiyeli, intradural lipom, siringomyeli, Chiari malformasyonu, gergin omurilik ve spinal kapanma defektleri (4). Bu bulgular oluşum kusurlarından çok, ayrışma kusurlarına ve karma tipe eşlik eder. Konjenital skolyoza en sık eşlik eden intraspinal anomali ise gergin omurilik sendromudur (18). Bölgesel kıllanma artışı olması, cilt gamzesi, hemanjiyom ve nevüs varlığı, veya asimetrik karın refleksi gibi bulgular spinal kapanma defektlerinin klinik göstergeleri olabilir (4). Bu hastalarda kapsamlı bir nörolojik muayene gereklidir. Torakolumbar ve lumbar hemivertebrası olan her hasta Klippel-Feil sendromu veya servikal hemivertebra varlığı açısından değerlendirilmelidir $(1,4)$. Benzer şekilde torakolumbar konjenital anomalilerin kaudal regresyon sendromu veya sakral agenezi olarak adlandırılan ve işlevsel kapasitenin korunması için erken teşhis ve müdahale gerektiren durumla birlikte görülebilir (20).

Benzer şekilde, konjenital skolyoza eşlik eden genitoüriner, kas-iskelet, kardiyovasküler ve diğer sistemlerle ilişkili anomalilerin tanınması öncelikle iyi bir klinik muayene ile başlar. Şüphe varlığında ek anomali ile ilgili branş tarafından konsülte edilmelidir. Kas-iskelet sisteminde sıklıkla konjenital skolyoza eşlik eden anomaliler gelişimsel kalça displazisi ve Sprengel deformitesidir (4). Eşlik eden anomalilerin atlanmaması için konjenital skolyoz teşhis edilen her hastada ekokardiyografi (1) ve böbrek ultrasonografisi ve MR incelemesi (4) önerilmektedir. Özellikle karma tip deformitelere göğüs kafesi ve kaburga anomalileri de eşlik edebilir ve torasik yetmezlik ile sonuçlanabilir $(2,12)$. Eşlik eden çeşitli anomaliler sporadik olarak bulunabileceği gibi VACTERL (V: vertebral, A: anal, C: kardiyak, TE: trakeo-özefageal, R: renal, L: ekstremite) gibi sendromlar ile de ilişkili olabilir (12).

\section{Tedavi}

Konjenital skolyozun tedavisi düzenli aralıklarla takip etmekten erken cerrahi müdahaleye kadar değişebilir. Başarılı tedavi uygun zamanlama ve minimal girişim ile yapılan müdahalelerden oluşur (1). Tedavi temel olarak kontrollü gözlem, konservatif ve cerrahi tedavilerden oluşur.

\section{Kontrollü gözlem}

Kontrollü gözlem belirli aralıklarla yapılan klinik muayene, fotoğraf çekimi ve röntgenler ile gerçekleştirilir. Takip aralıkları deformitenin tipine ve çocuğun yaşına göre belirlenir. Aralıklar genel olarak 6 ay olarak belirlense de ilk 3 yaş ve ergenlik gibi hızı büyüme dönemlerinde daha yakın takip gerekebilir (2). Cobb açı ölçümlerinin hangi vertebralardan alındığı, sonraki kontrollerde karşılaştırılabilirlik açısından kaydedilmelidir (11). Eşlik eden patolojilerin varIığında hastanın ilgili branşlara da düzenli gitmesi önerilir. 


\section{Konservatif tedavi}

Konjenital skolyotik eğrilikler genellikle esnek olmadıkları için korse tedavisi etkili değildir. Kompensatuar eğriliklerin kontrolü için korse kullanılabilir (2) Daha güncel çalışmalarda seri derotasyon alçılamanın eğriliğin ilerlemesini yavaşlatabileceği ve cerrahi müdahale yaşını geciktirebileceğine dair bulgular mevcuttur (4).

\section{Cerrahi tedavi}

Cerrahi tedavide en eski yaklaşım in-situ füzyondur. Tekli hemivertebra varlığında hemivertebrektomi ve limitli füzyon ameliyatı ile düzeltici cerrahi uygulanabilir. Daha karmaşık deformitelerde büyümeyi düzenleyen hemiepifizyodez (koveks büyüme arresti) veya büyümeyi uyaran omurga veya kaburga destekli distraksiyon temelli füzyonsuz sistemler veya büyümeyi yönlendiren teknikler uygulanabilir. Bu yöntemlerin birlikte kullanıldığı çeşitli modifikasyonlar ve hibrid tetkikler tanımlanmıştır. İhmal edilmiş vakalarda düzeltici osteotomiler gerekli olabilir. Cerrahi tedaviler sadece posterior yaklaşımla uygulanabileceği gibi kombine anterior-posterior yaklaşım da uygulanabilir.

\section{In-situ füzyon}

Posterior in-situ füzyon, faset rezeksiyonu, dekortikasyon ve bol miktarda kemik grefti yerleştirilmesi ile artrodez ve füzyon sağlanması şeklinde uygulanan en eski prosedürlerden birisidir (7). Ancak önde açık kalan diskler ve gövdeler aracılığılla anteriordan büyümenin devam etmesi ile yüksek oranda ilerlemeye neden olan krankşaft fenomeni gözlendiği için bu prosedür büyük oranda terk edilmiştir $(21,22)$.

\section{Hemivertebrektomi + limitli füzyon}

Hemivertebrektomi, kısmi ve tam ayrışmış hemivertebraya bağlı gelişen konjenital skolyozların tedavisinde etkili bir yöntemdir (2). Özellikle tam ayrışmış hemivertebralarda ilerleme potansiyeli yüksek olduğundan erken müdahale önemlidir. Kombine anterior-posterior yaklaşımla uygulanabilse de güncel birçok makale sadece posterior yaklaşımla güvenli, etkili ve daha az invaziv olarak hemivertebrektominin yapılabileceğini göstermiştir (16,23-25).

Ameliyatta düzeltmenin kolaylaştırılması, implant yetmezliği riskinin azaltılması ve ameliyat sonrası korseleme ihtiyacının azaltılması için supra- ve infra-laminar çengeller ile desteklenen 3-rod tekniği kullanılabilir (26) (Şekil 1). Hemivertebra rezeksiyonu ilk olarak torakolumbar bileşke ve lomber omurga için tanımlanmış olmakla birlikte daha güncel yayınlarda kord seviyesinde de bu ameliyatın güvenle yapılabildiği gösterilmiştir (27). Lumbosakral bileşkedeki hemivertebralar genelde ciddi pelvik oblikite ile sonuçlanır. Bu seviyede hemivertebrektomi, diğer tedavi yöntemlerine göre belirgin olarak daha iyi sonuçlara sahiptir (12).

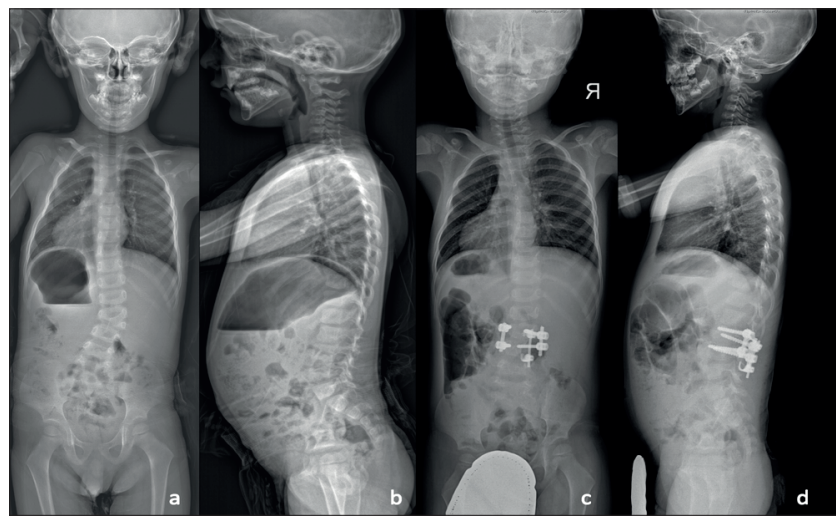

Şekil 1. L2-L3 arası aksesuar kısmen ayrışmış hemivertebrası olan 3 yaş 1 aylık erkek hastanın ameliyat öncesi a) ön-arka ve b) yan grafileri. Konkav tarafta pedikülleri, konveks tarafta ise hem pedikülleri hem de laminaları enstrümante ederek uygulanan 3-rod tekniği ile stabilizasyon uygulanarak yapılan hemivertebrektomi ve limitli füzyon ameliyatı sonrası c) ön-arka ve d) yan grafileri.

Hemivertebrektomi ameliyatları tecrübe gerektiren, teknik olarak zor ameliyatlardır. Deneyimli ellerde, uygun teknik ile uygulandığında in-situ füzyona ve hemiepifizyodeze göre daha başarılı sonuçlar bildirilmiştir (2). Genel olarak 5 yaş altında yapılsa da limitli füzyon alanının en kısa segmentte tutulabilmesi için 2 yaş civarında yapılması önerilir (12). Daha güncel bir yayında hemivertebrektomi ve kısa segment füzyon uygulandığında ortalama yaşları 6.6 olan onsekiz hastanın ortalama 11.4 yıl takibinde başarılı sonuçlar bildirilmiştir (28).

Hemiepifizyodez (Konveks büyüme arresti)

Hemiepifizyodez, eğriliğin konkav tarafı ekspoze edilmeden sadece konveks tarafına uygulanan füzyon işlemini tanımlar. Yeterli büyüme potansiyeli olan hastada, konveks taraftaki büyümeyi engellerken konkav tarafta normal büyüme devam ettiği için tedrici olarak eğriliği düzelten güvenli ve etkili bir yöntemdir (29). Sadece posterior yaklaşımla uygulanabilse de klasik yöntem kombine anterior-posterior yaklaşım ile konveks tarafta ön ve arkaya uygulanan füzyon işlemidir (30). Daha güncel deneysel çalışmalar ile sadece posterior pedikül vidaları ile uygulanan hemiepifizyodez ile vertebranın anterior büyümesinin de kontrol edilebileceği ve böylece anterior cerrahiye olan ihtiyacın azaltılabileceği gösterilmiştir (31).

Konveks büyüme arrestinin yeterli ve etkili olabilmesi için uygun hasta seçimi çok önemlidir. Çeşitli çalışmalarda endikasyonlar, skolyotik eğriliğin ilerleyici ve 70 derecenin altında olması, eğriliğin 5 veya daha az vertebral segmentten kaynaklanması, hastanın 5 yaşından küçük olması, ciddi kifotik veya lordotik komponentin olmaması, servikal tutulum olmaması, meningomyelosel olmaması ve konjenital skolyoz etyolojisinin unilateral bar olmaması olarak belirlenmiştir (32-34). 
Hemiepifizyodez tekniği ile başarılı sonuçlar bildirilmesine rağmen erken yaşta anterior cerrahi gerektirmesi, eğriliğin ameliyat sonrasında nasıl davranacağının tam olarak öngörülememesi (35) ve \%8 ile \%21 arasında değişen başarısızlık oranları bildirilmesi (36) nedeniyle bu tekniğin modifikasyonları önerilmiştir (37-39) (Şekil 2). Bu modifikasyonlarda konveks büyüme arrestine, konkav taraftan distraksiyon eklenmiştir. Böylece büyümeyi düzenleyen ve uyaran yöntemler hibrid olarak birlikte kullanılmış olmaktadır. Bu modifikasyonla koronal düzelme daha yüksek miktarda olmaktadır. Aynı zamanda göğüs kafesi gelişimi desteklenmektedir. Osteotomiler gibi daha büyük ve karmaşık cerrahilere olan ihtiyacı azaltabilmektedir (37).

\section{Distraksiyon temelli füzyonsuz tedaviler}

Konjenital skolyozlu çocuklarda genel olarak gövde boyu kısadır. Füzyon uygulanması, göğüs kafesi uzunluğunun ve gövde boyunun daha da kısa kalmasına sebep olabilir. Bu nedenle, füzyonsuz subkutan enstrümantasyon ve tekrarlayan uzatmalar ile eğrilik kontrol edilirken büyümenin de uyarılması teknikleri konjenital skolyozda uygulanabilir $(40,41)$. Konvansiyonel büyüyen rod uygulamalarında üst ve alt bağlanma noktaları (vida-çengel) omurga üzerindedir. Bu noktalardan biri veya ikisi kaburga üzerine kurularak göğüs kafesi temelli distraksiyonlar da uygulanabilir (42).

Daha güncel olarak büyüyen rod uygulamaları için manyetik kontrollü uzatmaya imkan veren sistemler de geliştirilmiştir (4) (Şekil 3). İmplantasyon aşaması ve çalışma prensipleri konvansiyonel büyüyen rod uygulamaları ile aynı olmakla birlikte, manyetik kontrollü sistemler poliklinik şartlarında ağrı kesici, sedasyon veya anestezi
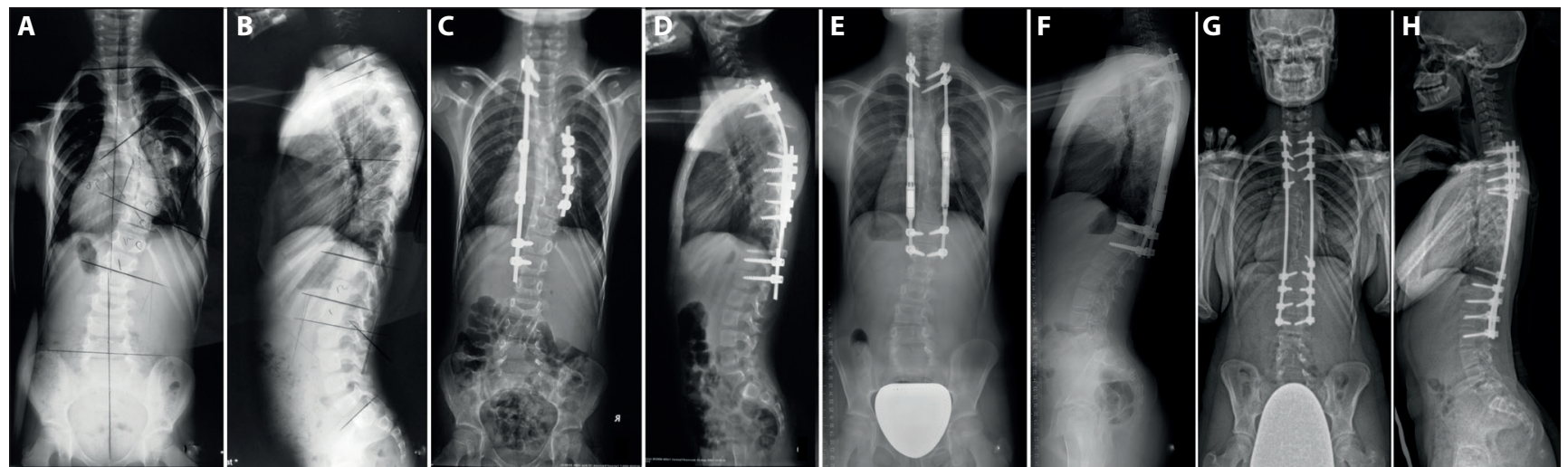

Şekil 2. T6-T10 vertebraları ilgilendiren konkav tarafta unsegmente bar ve konveks tarafta kama vertebraları bulunan 5 yaşında kız hastanın ameliyat öncesi A) ön-arka ve B) yan grafileri. Hastaya hibrid yöntemle konveks hemiepifizyodez ve konkav distraksiyon uygulandıktan sonra C) ön-arka ve D) yan grafileri. 6 uzatma sonrası rodda pay kalmadığı için konkav distraskiyon sistemi manyetik kontrollü büyüyen rod ile değiştirildi. Bu rod da tamamıyla uzatıldıktan sonra hasta 10 yaşında Risser 0, Sanders 2 ve kemik yaşı 9 yaş ile uyumlu olduğu için konveks hemiepifizyodeze ait implantlar çıkarılarak yapılan bilateral manyetik kontrollü büyüyen rod uygulaması sonrası E) ön-arka ve F) yan grafileri. Hasta 14 yaşına geldiğinde definitif füzyon ameliyatı uygulandı. Füzyon ameliyatı sonrası 1 yıl takipteki G) ön-arka ve H) yan grafileri.
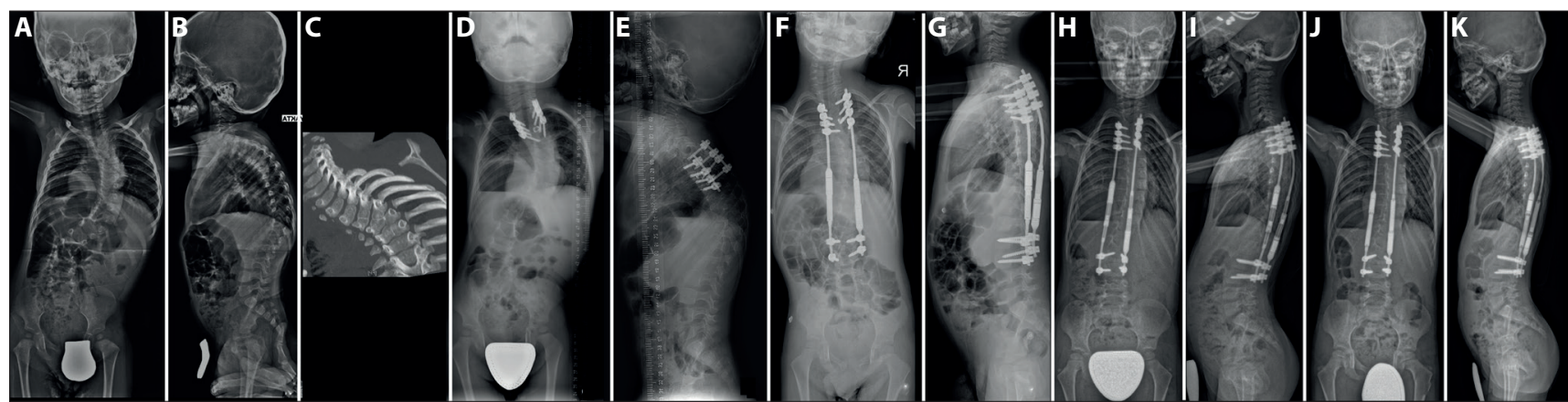

Sekil 3. T5 hemivertebra, anal atrezisi, böbrekte şekil bozukluğu, sol kol ve sol bacakta kuvvet azlığı ve kalbin apeksinin sağa bakması ile kliniğe yansımış 2 yaşında erkek VACTERL hastasının ameliyat öncesi A) ön-arka, B) yan grafileri ve C) bilgisayarlı tomografi görüntüsü. Hemivertebrektomi ve limitli füzyon ile üst torakal deformitesi düzeltildikten 1 yıl sonra takipteki D) ön-arka ve E) yan grafileri. Takiplerde korseleme ile zaman kazanıldıktan sonra hasta 4 yaşına geldiğinde uygulanan manyetik kontrollü büyüyen rod sonrası $\mathbf{F}$ ) ön-arka ve $\mathbf{G}$ ) yan grafileri. Takiplerde hızlı büyüme dönemiyle de uyumlu şekilde rodları sık aralıklarla uzatılan hastada 2 yı takip sonunda $\mathbf{H}$ ) ön-arka ve I) yan grafileri. Hasta 6 yaşında yapılan üçüncü ameliyat ile rodları yenileri ile değiştirildikten sonra J) ön-arka ve K) yan grafileri. Hasta bu makalenin yazııdığı dönemde son ameliyat sonrası 6 ay takibini tamamladı ve uzatmaları devam ediyor. 
ihtiyacı olmadan uzatılmaya imkan sağlarlar. Bu şekilde her hasta için yapılan ameliyat sayısı önemli ölçüde azaltılabilmektedir.

Göğüs kafesi ve kaburga temelli sistemler konjenital skolyoza eşlik edebilen torasik yetmezlik sendromunun da eş zamanlı tedavisini sağlamak amacıyla geliştirilmiştir (43). Konjenital skolyozla birlikte kosta anomalilerinin de olduğu durumlarda ekspansiyon torakoplasti ile birlikte kosta temelli büyüyen rod uygulamaları etkin bir tedavi seçeneğidir (42).

\section{Büyümenin yönlendirilmesi}

Her ne kadar manyetik kontrollü uygulamalar tekrarlayan ameliyat sayısını azaltmış olsa da, distraksiyon temelli sistemlerde tekrarlayan prosedürler gerekir. Büyümeyi yönlendiren Shilla veya modifiye Luque-trolley gibi sistemler apikal kontrol sağlarken büyümenin de istenilen yöne doğru olmasını sağlarlar (9).

\section{Düzeltici osteotomiler}

Bazı ihmal edilmiş veya kötü tedavi edilmiş vakalarda, eğrilik çok ileri ve sert olabilir. Bu gibi durumlarda yukarıda tartışılan cerrahi tedavi yöntemleri yetersiz kalabilir. Artmış pelvik oblikite, gövde dekompensasyonu ve nörolojik defisit varlığı da osteotomi gereksinimine neden olabilir (12). Benzer şekilde daha önce füzyon yapılmış deforme füzyon kitlelerin tedavisinde de osteotomiler kullanılabilir (Şekil 4). İhmal edilmiş ve ileri vakalarda vertebral kolon rezeksiyonu etkin bir yöntemdir $(44,45)$. Bu yöntem çıkarılan segmente ek en az 4-6 segment daha füzyon gerektirdiği, nörolojik hasarlanma riski barındırdığı ve teknik olarak zor uygulanabilir olduğu için (45) yalnızca donanımlı merkezlerde ve deneyimli ellerde gerçekleştirilmelidir. Özellikle kompleks konjenital skolyoz olgularında anormal pedikül varlığında intraoperatif BT ve navigasyon kullanımı ile daha güvenli pedikül vidası yerleştirilmesinin sağlanabilmesi mümkün olabilir (46).
Eşlik eden spinal intra-dural patolojilerde cerrahi tedavi Geçmiş yıllarda spinal intradural patolojinin spinal deformiteye eşlik ettiği hastalarda genellikle aşamalı cerrahi uygulanırdı. Öncelikle beyin cerrahisi bölümünce gergin omurilik sendromu, diastematomiyeli ve benzeri spinal intradural patoloji ameliyat edilir, daha sonra başka seansta ortopedi uzmanı tarafından spinal deformite cerrahisi yapılırdı. Günümüzde teknolojik ilerlemeler, özellikle intraoperatif nöromonitörizasyon sayesinde spinal deformite ve intradural patolojilerin cerrahisi eş zamanlı yapılabilir hale gelmiştir. Yapılan güncel bir çalışmada aynı seansta yapılan spinal ve intraspinal cerrahinin güvenli ve etkili olduğu bildirilmiştir (47) (Şekil 5).

\section{Komplikasyonlar}

Genel olarak konjenital skolyozun cerrahi tedavisinde komplikasyon oranları literatürede $\% 14$ olarak bildirilmiştir (48). Skolyoz etyolojileri içerisinde nörolojik komplikasyonların en fazla görüldüğü tip \%9'luk bir oranla konjenital skolyozdur (48). Implant yetmezliği, enfeksiyon, eğriliklerin ilerlemesi ve benzeri komplikasyonlara bağlı olarak ilave cerrahiler gerekebilmektedir (49).

\section{Sonuç}

Konjenital spinal deformitelerin tanısında ve takibinde klinik muayene ve eşlik edilen anomalilerin araştırılması büyük önem taşır. Takip ve tedavide temel amaç dengeli bir gövde elde ederken omurganın büyümesine de mümkün mertebe izin vermektir. Hastanın yaşına, deformitenin tipine ve her deformite tipine göre doğal seyre bakılarak her hasta için özelleştirilmiş tedavi kararı verilir. Tek bir hemivertebra varlığında genellikle erken yaşta hemivertebrektomi ve limitli füzyon önerilir. Daha ileri deformitelerde hemiepifizyodez, distraksiyon temelli füzyonsuz cerrahi yöntemler veya bunların kombinasyonları kullanılabilir. İhmal edilmiş ileri deformitelerde düzeltici osteotomiler gerekebilir.
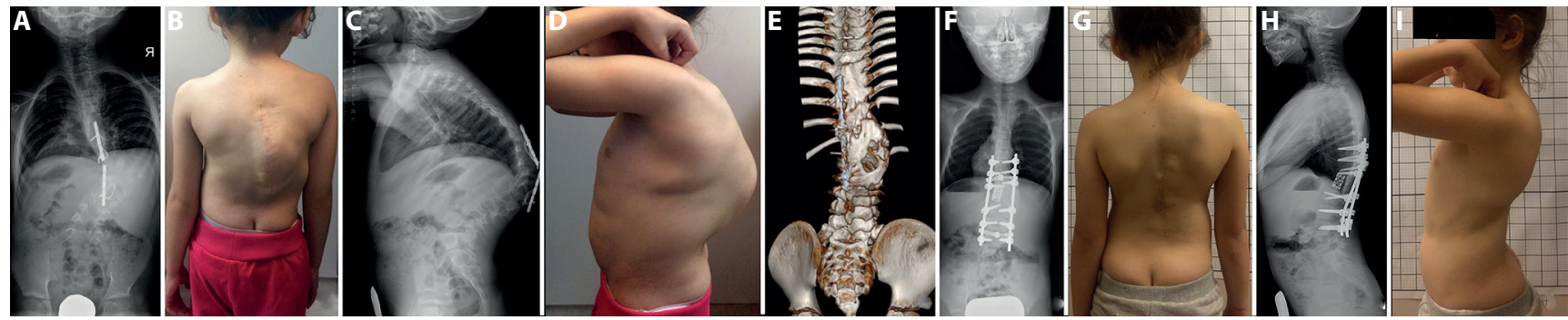

Şekil 4. T12 ve L1'de posterolateral hemivertebralar ile torakolumbar kifoskolyotik eğriliği olan 6 yaşında kız hasta, kliniğimize başvurmadan önce 6 kez ameliyat olmuştu. 3 ameliyatı deformite düzeltmeye yönelik, 3 ameliyatı ise debridman için uygulanmıştı. Hasta kliniğimize başvurduğundaki radyografik ve klinik

A, B) ön-arka ve C,D) yan görüntüleri. Hastada e) geniş füzyon kitlesi ve torakolumbar bileşkede kaynamama mevcuttu. Hastaya T12 ve L1 vertebral kolon rezeksiyonu ve füzyon uygulandı. Hastanın 1 yıl takip sonrası radyografik ve klinik $\mathbf{F}, \mathbf{G}$ ) ön-arka ve $\mathbf{H , i}$ ) yan görüntüleri. 

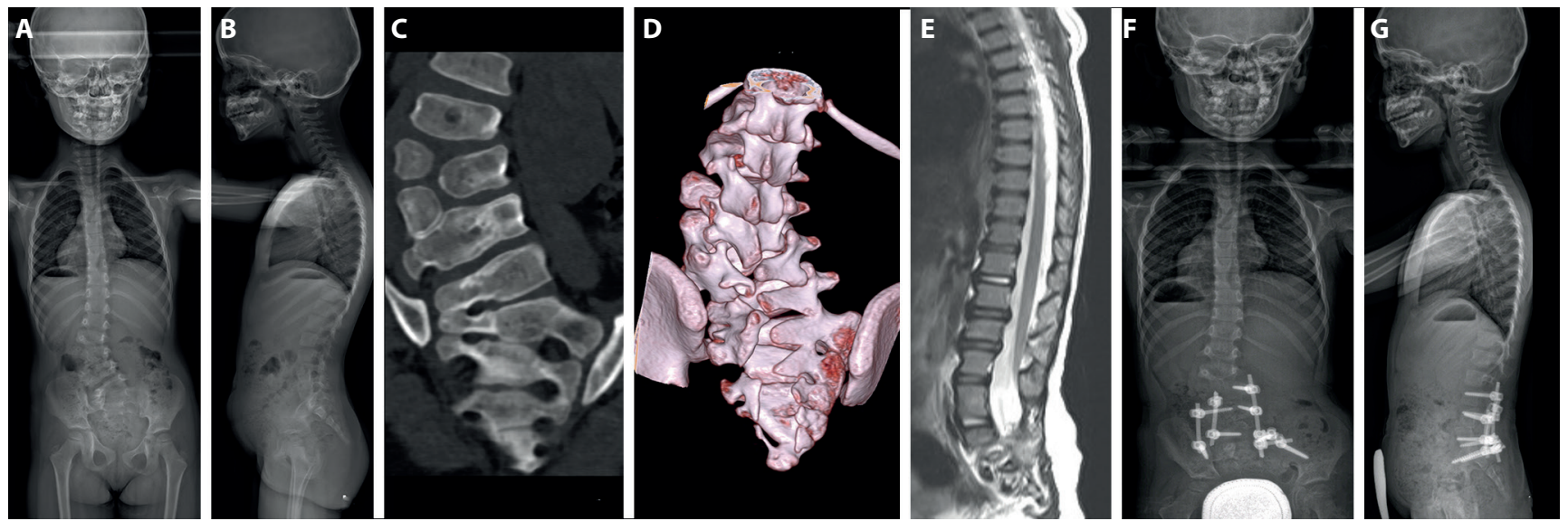

Şekil 5. L3 kelebek vertebra, L3-L4 arası aksesuar kısmen ayrışmış hemivertevra, L5-S1-S2 arasında solda unsegmente bar, sol hemi-sakral agenezi ve L4 ile ilyak kanat arası psödo-eklemleşme olan 6 yaşında konjenital skolyoz hastasının ameliyat öncesi a) ön-arka, b) yan grafileri c) koronal ve d) 3-boyutlu tomografi görüntüleri. Hastanın çekilen e) MR'larında gergin omurilik ve fatty-filum anomalileri saptandı. Hastaya Pediatrik Beyin Cerrahisi ve Ortopedik Omurga Cerrahisi ekiplerince eş zamanlı cerrahi ile fatty-filum terminale kesilmesi, L3-S1-ilyak posterior enstürmantasyon, L3-L4 arası sol aksesuar hemivertebraya hemivertebrektomi, L5'e sağ hemikorpektomi, sol L5-S1-S2 arasındaki unsegmente barın rezeksiyonu, L4-ilyak kanat arası psödo-eklemin açıması ve her iki tarafta çift rod ile stabilizasyon ve füzyon uygulandı. Hastanın ameliyatı sonrası f) ön-arka ve g) yan grafileri.

\section{Kaynaklar}

1. Arlet V, Odent T, Aebi M. Congenital scoliosis. Eur Spine J 2003;12:45663. [CrossRef]

2. Tsirikos Al, McMaster MJ. Congenital anomalies of the ribs and chest wall associated with congenital deformities of the spine. J Bone Joint Surg Am 2005;87:2523-36. [CrossRef]

3. Giampietro PF. Genetic aspects of congenital and idiopathic scoliosis. Scientifica (Cairo) 2012;2012:152365. [CrossRef]

4. Pahys JM, Guille JT. What's New in Congenital Scoliosis? J Pediatr Orthop 2018;38:e172-e9. [CrossRef] https://doi.org/10.1097/ BPO.0000000000000922.

5. Kaplan KM, Spivak JM, Bendo JA. Embryology of the spine and associated congenital abnormalities. Spine J 2005;5:564-76. [CrossRef]

6. Grimme JD, Castillo M. Congenital anomalies of the spine. Neuroimaging Clin N Am 2007;17:1-16. [CrossRef]

7. Hedequist D, Emans J. Congenital scoliosis: a review and update. J Pediatr Orthop 2007;27:106-16. [CrossRef]

8. Li Z, Yu X, Shen J. Environmental aspects of congenital scoliosis. Environ Sci Pollut Res Int 2015;22:5751-5. [CrossRef]

9. Burnei G, Gavriliu S, Vlad C, et al. Congenital scoliosis: an up-to-date. J Med Life 2015;8:388-97.

10. Hedequist DJ, Emans JB. The correlation of preoperative threedimensional computed tomography reconstructions with operative findings in congenital scoliosis. Spine 2003;28:2531-4; discussion 1. [CrossRef]

11. Tauchi R, Tsuji T, Cahill PJ, et al. Reliability analysis of Cobb angle measurements of congenital scoliosis using X-ray and 3D-CT images. Eur J Orthop Surg Traumatol 2016;26:53-7. [CrossRef]

12. Hedequist D, Emans J. Congenital scoliosis. J Am Acad of Orthop Surg 2004;12:266-75.

13. Jaskwhich D, Ali RM, Patel TC, Green DW. Congenital scoliosis. Curr Opin Pediatr 2000;12:61-6.

14. McMaster MJ, Ohtsuka K. The natural history of congenital scoliosis. A study of two hundred and fifty-one patients. J Bone Joint Surg Am 1982;64:1128-47.
15. Johal J, Loukas M, Fisahn C, Chapman JR, Oskouian RJ, Tubbs RS. Hemivertebrae: a comprehensive review of embryology, imaging, classification, and management. Child's Nerv Syst 2016;32:2105-9. [CrossRef]

16. Feng Y, Hai Y, Zhao S, Zang L. Hemivertebra resection with posterior unilateral intervertebral fusion and transpedicular fixation for congenital scoliosis: results with at least 3 years of follow-up. Eur Spine J 2016;25:3274-81. [CrossRef]

17. Shawen SB, Belmont PJ, Jr., Kuklo TR, et al. Hemimetameric segmental shift: a case series and review. Spine 2002;27:E539-44. [CrossRef]

18. Basu PS, Elsebaie H, Noordeen MH. Congenital spinal deformity: a comprehensive assessment at presentation. Spine 2002;27:2255-9. [CrossRef]

19. Marks DS, Qaimkhani SA. The natural history of congenital scoliosis and kyphosis. Spine 2009;34:1751-5. [CrossRef]

20. Balioglu MB, Akman YE, Ucpunar $\mathrm{H}$, et al. Sacral agenesis: evaluation of accompanying pathologies in 38 cases, with analysis of long-term outcomes. Child's Nerv Syst 2016;32:1693-702. [CrossRef]

21. Dubousset J, Herring JA, Shufflebarger H. The crankshaft phenomenon. J Pediatr Orthop 1989;9:541-50.

22. Kesling KL, Lonstein JE, Denis F, et al. The crankshaft phenomenon after posterior spinal arthrodesis for congenital scoliosis: a review of 54 patients. Spine 2003;28:267-71. [CrossRef]

23. Zhuang Q, Zhang J, Li S, Wang S, Guo J, Qiu G. One-stage posterioronly lumbosacral hemivertebra resection with short segmental fusion: a more than 2-year follow-up. Eur Spine J 2016;25:1567-74. [CrossRef]

24. Guo J, Zhang J, Wang S, et al. Surgical outcomes and complications of posterior hemivertebra resection in children younger than 5 years old. J Orthop Surg Res 2016;11:48. [CrossRef]

25. Piantoni L, Francheri Wilson IA, Tello CA, et al. Hemivertebra Resection With Instrumented Fusion by Posterior Approach in Children. Spine Deform 2015;3:541-8. [CrossRef]

26. Hedequist D, Emans J, Proctor $M$. Three rod technique facilitates hemivertebra wedge excision in young children through a posterior only approach. Spine 2009;34:E225-9. [CrossRef] 
27. Ruf $M$, Harms J. Hemivertebra resection by a posterior approach: innovative operative technique and first results. Spine 2002;27:1116-23.

28. Chang DG, Kim JH, Ha KY, Lee JS, Jang JS, Suk SI. Posterior hemivertebra resection and short segment fusion with pedicle screw fixation for congenital scoliosis in children younger than 10 years: greater than 7-year follow-up. Spine 2015;40:E484-91. [CrossRef]

29. Uzumcugil A, Cil A, Yazici M, et al. The efficacy of convex hemiepiphysiodesis in patients with iatrogenic posterior element deficiency resulting from diastematomyelia excision. Spine 2003;28:799-805.

30. Kieffer J, Dubousset J. Combined anterior and posterior convex epiphysiodesis for progressive congenital scoliosis in children aged $<$ or $=5$ years. Eur Spine J 1994;3:120-5.

31. BekmezS, Demirkiran HG, YilmazG, etal. ConvexHemiepiphysiodesis: Posterior/anterior in-situ Versus Posterior-only With Pedicle Screw Instrumentation: An Experimental Simulation in Immature Pigs. J Pediatr Orthop 2016;36:847-52. [CrossRef]

32. Andrew T, Piggott H. Growth arrest for progressive scoliosis. Combined anterior and posterior fusion of the convexity. J Bone Joint Surg Br 1985;67:193-7.

33. Bradford DS. Partial epiphyseal arrest and supplemental fixation for progressive correction of congenital spinal deformity. J Bone Joint Surg Am 1982;64:610-4.

34. Keller PM, Lindseth RE, DeRosa GP. Progressive congenital scoliosis treatment using a transpedicular anterior and posterior convex hemiepiphysiodesis and hemiarthrodesis. A preliminary report. Spine 1994;19:1933-9.

35. Uzumcugil A, Cil A, Yazici M, et al. Convex growth arrest in the treatment of congenital spinal deformities, revisited. J Pediatr Orthop 2004;24:658-66.

36. Walhout RJ, van Rhijn LW, Pruijs JE. Hemi-epiphysiodesis for unclassified congenital scoliosis: immediate results and mid-term follow-up. Eur Spine J 2002;11:543-9. [CrossRef]

37. Demirkiran G, Dede O, Ayvaz M, Bas CE, Alanay A, Yazici M. Convex Instrumented Hemiepiphysiodesis With Concave Distraction: A Treatment Option for Long Sweeping Congenital Curves. J Pediatr Orthop 2016;36:226-31. [CrossRef]

38. Cheung KM, Zhang JG, Lu DS, K Luk KD, Y Leong JC. Ten-year followup study of lower thoracic hemivertebrae treated by convex fusion and concave distraction. Spine 2002;27:748-53.
39. Alanay A, Dede O, Yazici M. Convex instrumented hemiepiphysiodesis with concave distraction: a preliminary report. Clin Orthop Relat Res 2012;470:1144-50. [CrossRef]

40. Elsebai HB, Yazici M, Thompson GH, et al. Safety and efficacy of growing rod technique for pediatric congenital spinal deformities. J Pediatr Orthop 2011;31:1-5. [CrossRef]

41. Yazici M, Emans J. Fusionless instrumentation systems for congenital scoliosis: expandable spinal rods and vertical expandable prosthetic titanium rib in the management of congenital spine deformities in the growing child. Spine 2009;34:1800-7. [CrossRef]

42. Emans JB, Caubet JF, Ordonez CL, Lee EY, Ciarlo M. The treatment of spine and chest wall deformities with fused ribs by expansion thoracostomy and insertion of vertical expandable prosthetic titanium rib: growth of thoracic spine and improvement of lung volumes. Spine 2005;30:S58-68.

43. Campbell RM Jr., Smith MD, Mayes TC, et al. The characteristics of thoracic insufficiency syndrome associated with fused ribs and congenital scoliosis. J Bone Joint Surg Am 2003;85-A:399-408.

44. Ozturk C, Alanay A, Ganiyusufoglu K, Karadereler S, Ulusoy L, Hamzaoglu A. Short-term X-ray results of posterior vertebral column resection in severe congenital kyphosis, scoliosis, and kyphoscoliosis. Spine 2012;37:1054-7. [CrossRef]

45. Lenke LG, O'Leary PT, Bridwell KH, Sides BA, Koester LA, Blanke KM Posterior vertebral column resection for severe pediatric deformity: minimum two-year follow-up of thirty-five consecutive patients. Spine 2009;34:2213-21. [CrossRef]

46. Larson AN, Polly DW Jr., Guidera KJ, et al. The accuracy of navigation and $3 \mathrm{D}$ image-guided placement for the placement of pedicle screws in congenital spine deformity. J Pediatr Orthop 2012;32:e239. [CrossRef]

47. Yilgor C, Sogunmez N, Dalla M, et al. Eş Zamanlı İntradural Spina Patoloji ve Pediatrik Spinal Deformite Cerrahisi. Türk Nöroşirürji Derneği 31 Bilimsel Kongresi; 2017; Antalya.

48. Weiss HR, Goodall D. Rate of complications in scoliosis surgery - a systematic review of the Pub Med literature. Scoliosis 2008;3:9. [CrossRef]

49. Ruf $M$, Jensen R, Letko L, Harms J. Hemivertebra resection and osteotomies in congenital spine deformity. Spine 2009;34:1791-9. [CrossRef] 